\title{
Salvage forearm to arm replantation
}

\author{
Ravikiran Naalla 두, Maneesh Singhal, Rakesh Dawar 다, Manish Maurya
}

Plastic Reconstructive and Burns Surgery, All India Institute of Medical Sciences, New Delhi, India

\section{Correspondence to} Professor Maneesh Singhal; drmaneesh@gmail.com

Accepted 1 July 2020

\section{DESCRIPTION}

A 20-year-old woman presented to us with a crush avulsion amputation of the right upper limb at the level of forearm following a sideswipe injury. She was a right-handed person. The warm ischaemia time was 6 hours. She had a comminuted fracture of both bones of the forearm and severely crushed upper and middle third segments of radius and ulna. The elbow joint was unsalvageable. The patient was counselled about the shortening of the upper limb following a successful replantation.

The amputated part was taken up for debridement of the muscles, tagging of the tendons and neurovascular structures. Meanwhile, the patient was stabilised and prepared for the surgery. Under general anaesthesia the patient's arm was debrided; tendons and neurovascular structures were tagged. Skeletal fixation was achieved using an external fixator and a K-wire. The arterial anastomosis was performed between brachial and radial arteries. One of the radial venae comitantes was anastomosed to one of the brachial veins. The basilic vein was repaired. After appropriate tensioning, all the flexor digitorum profundus and flexor pollicis longus tendons were weaved into biceps tendon with
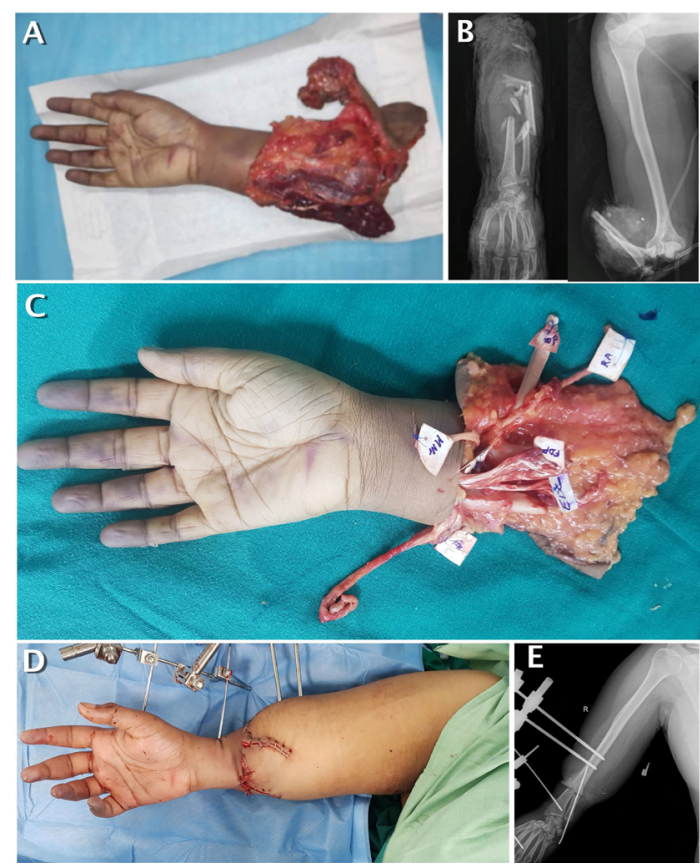

Figure 1 Image showing (A) right forearm amputated stump, (B) comminuted both bone forearm fractures, (C) debridement of forearm muscles and tagging of structures, (D) successful replantation, (E) skeletal fixation.
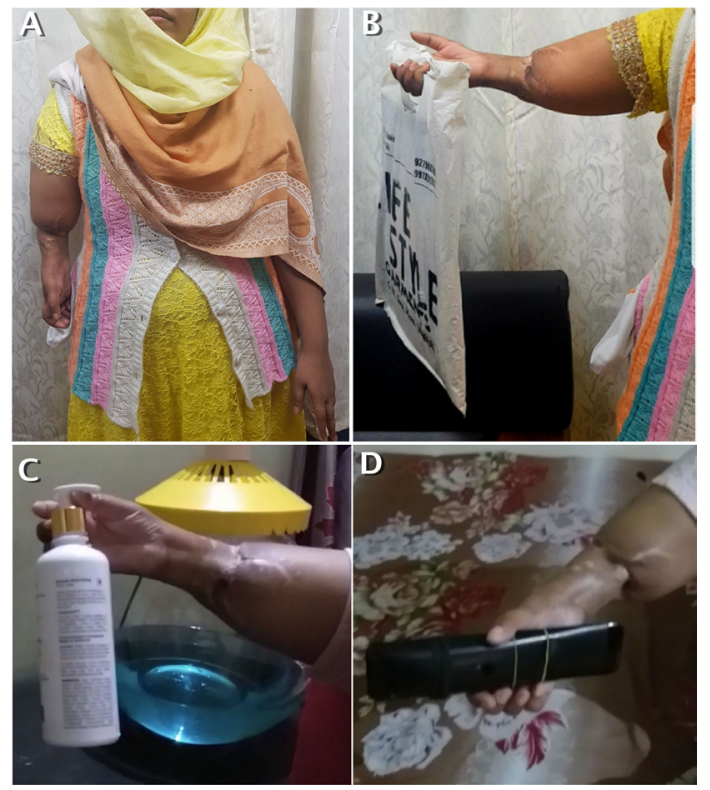

Figure 2 Image showing (A) postoperative appearance, $(B, C, D)$ functional outcome in terms of holding objects.

3-0 polypropylene sutures using the Pulvertaft technique. Similarly, extensor digitorum communis of all fingers and extensor pollicis longus were sutured to the triceps tendon. The median and ulnar nerves were primarily repaired with 10-0 polyamide sutures. The duration of surgery was 6 hours. The replantation was successful (figure 1) and the postoperative stay was uneventful.

Physiotherapy was started after a week of surgery. The external fixator and K-wire were removed after 8 weeks and a below-elbow cast was applied for 4 weeks. She was instructed to contract biceps for finger flexion and triceps for finger extension. With regular physiotherapy strength gradually improved. After 9 months of follow-up, the patient has achieved active flexion and extension of fingers along with palmar abduction of the thumb. She has a strong hook grip. The thenar muscles motor recovery was M3 and is improving. She has poor ulnar nerve recovery which is evidenced by clawing of fingers. She has $\mathrm{S} 3+$ and $\mathrm{S} 2+$ sensory recovery in the median and ulnar nerve distribution, respectively (as per modified British Medical Research Council Score for sensory recovery). ${ }^{1}$ The patient has got adjusted to her short upper extremity and is using the hand for the day today activities. Though the function of the hand can be further improved by tenolysis and neurolysis, the patient has refused to undergo any surgical procedure. 


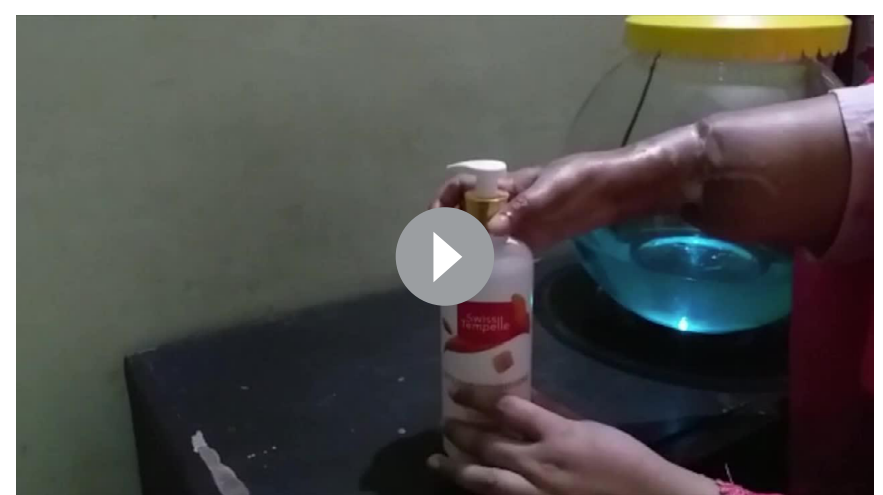

Video 1. Ability of the patient to use the reconstructed right upper limb in day-to-day activities.

\section{Patient's perspective}

I was shocked when I realised that I had lost my right hand. I'm blessed to have my hand back. Though it is short, I can feel the objects and I can use it in many ways. The best thing is people don't see and discriminate me as an amputee!

\section{Learning points}

Radical debridement of devitalised muscle, adequate bone shortening/fixation, primary repair of nerves and strategies to reduce ischaemia time are critical to achieving a good functional outcome in any major replantation.

- Though distal forearm to arm replantation results in a significant shortening of the limb, it provides an acceptable hand function.
Replantation is preferred to stump closure and prosthesis application as the former has an advantage of sensation and psychological well-being. ${ }^{2}$ In any major replantation, radical debridement of devitalised muscle, adequate bone shortening/fixation, primary repair of nerves and strategies to reduce the ischaemia time are critical to achieving a good functional outcome. ${ }^{3}$ In our patient, the replantation has resulted in a significant shortening of the limb in addition to the loss of the elbow joint. There is poor ulnar nerve recovery. This might be attributable to the avulsion injury. The pronation and supination are partially compensated by the shoulder joint. In spite of these issues she has an acceptable hand function due to the good sensory recovery, an acceptable range of motion in the finger and thumb and a strong hook grip (figure 2). As seen in the video (video 1) the patient uses the reconstructed limb not only as a supportive limb but also as an independent one. Hence, forearm to arm replantation is an acceptable strategy and is worth performing the procedure.

Contributors $\mathrm{RN}$ is the operating surgeon and prepared the manuscript. MS is the professor in charge. RD is the consultant in charge. MM is involved in the rehabilitation.

Funding The authors have not declared a specific grant for this research from any funding agency in the public, commercial or not-for-profit sectors.

Competing interests None declared.

Patient consent for publication Obtained.

Provenance and peer review Not commissioned; externally peer reviewed.

\section{ORCID iDs}

Ravikiran Naalla http://orcid.org/0000-0001-7658-1073

Rakesh Dawar http://orcid.org/0000-0002-0951-1857

\section{REFERENCES}

1 Wang $Y$, Sunitha M, Chung KC. How to measure outcomes of peripheral nerve surgery. Hand Clin 2013:29:349-61.

2 Otto IA, Kon M, Schuurman AH, et al. Replantation versus prosthetic fitting in traumatic arm amputations: a systematic review. PLoS One 2015;10:e0137729.

3 Sabapathy SR, Venkatramani H, Bharathi RR, et al. Technical considerations and functional outcome of 22 major replantations (the BSSH Douglas lamb lecture, 2005). $J$ Hand Surg Eur Vol 2007;32:488-501.

Copyright 2020 BMJ Publishing Group. All rights reserved. For permission to reuse any of this content visit

https://www.bmj.com/company/products-services/rights-and-licensing/permissions/

BMJ Case Report Fellows may re-use this article for personal use and teaching without any further permission.

Become a Fellow of BMJ Case Reports today and you can:

- Submit as many cases as you like

- Enjoy fast sympathetic peer review and rapid publication of accepted articles

- Access all the published articles

- Re-use any of the published material for personal use and teaching without further permission

Customer Service

If you have any further queries about your subscription, please contact our customer services team on +44 (0) 2071111105 or via email at support@bmj.com.

Visit casereports.bmj.com for more articles like this and to become a Fellow 